\title{
Knowledge and Practice of Supporting Health Literacy for Older Adults Among Community Care Workers: A Cross-sectional Study in Community- based Integrated Support Centers
}

Yoko Aihara ( $\nabla$ yanzu99@gmail.com )

Kobe Gakuin University

Itsuko Ishihara

Kobe City College of Nursing

\section{Research Article}

Keywords: Community-based support centers, Health literacy, Older adults, Long-term care

Posted Date: January 12th, 2021

DOl: https://doi.org/10.21203/rs.3.rs-141576/v1

License: (c) (1) This work is licensed under a Creative Commons Attribution 4.0 International License. Read Full License 


\section{Abstract}

Background: Health literacy, as it relates to better decision-making and autonomy of self-care in older adults, is a growing concern. Health and care professionals play key roles in advocating and supporting health literacy of older adults. This cross-sectional study aimed to assess community care workers' knowledge and practice of supporting health literacy among their clients.

Methods: Structured questionnaires were posted to all community-based integrated support centers in two prefectures in Japan; care managers, nurses, and social workers were requested to participate in the study. Knowledge and practice of health literacy was compared based on professional qualifications. A Chi-square test was used for analyzing the differences of knowledge and practice of supporting health literacy by professional qualifications. A logistic regression was used for identifying factors associated with participants' health literacy.

Results: In total, 453 workers (care managers: $34 \%$; nurses: $31 \%$; and social workers: $35 \%$ ) responded. Only $9 \%$ of the respondents knew the term and definition of health literacy; and nurses were more likely to perceive the importance of improving and practicing to support the health literacy of clients, compared to care managers and social workers. Less than $10 \%$ of the respondents always use teach-back methods and visual materials, which are useful communication methods for low health literacy, for communication with clients.

Conclusions: The study suggests that knowledge and practice of supporting health literacy differ by professional qualifications. Older adults receive health and care information from a variety of staff in community-based support centers. Therefore, the study suggests the improvement of the communication skills of the community health and care workers, in order to support clients with low health literacy.

\section{Background}

Due to increase in the number of older adults and the morbidity of chronic illnesses, management of long-term care conditions is a key challenge in healthcare systems worldwide. Recent study implies that health literacy is a key indicator of quality of long-term care for older adults [1], because limited health literacy is associated with increased mortality, a higher prevalence of frailty, and poor patients' satisfaction and higher health care utilization and expenditure among older adults [2-4]. In addition, adequate health literacy skills are associated with better decision-making and decision-making styles among older adults $[5,6]$. Decision making becomes more complex for older people with multiple health and care needs as the capacity to self-manage is affected by the cumulative effects of long-term conditions [7]. Therefore, improving health literacy is a key strategy for aged care including managing health, improving quality of life, and improving decision-making $[3,8]$.

Improving individuals' health literacy level is one of the key strategies for promoting health and quality of long-term care for older adults; however, assessing an older adults' health literacy should be considered because older age is strongly associated with limited health literacy [9]. Linkage between health literacy 
and health outcome is not only influenced at the individual level, but also by health care providers and system factors $[10,11]$. According to the World Health Organization, health literacy was redefined as "personal characteristics and social resources needed for individuals and communities to access, understand, appraise and use information and services to make decisions about health [12]." Although such a framework implies that individual health literacy needs are identified, recent reports emphasize the responsiveness of health services, environments, and information products to support individuals' health literacy strengths and limitations $[12,13]$. Health literacy support by health providers is important to improve autonomy and patient-centered relationships with health professionals [14]. Adequate assessment and evaluation of health literacy by care providers as well as patient-care providers communication, based on health literacy level, are required for older adults. However, several studies have reported that limited awareness of health literacy [15-17], including an inadequate assessment of health literacy of the patients among health professionals [18]. Dickens et al. suggested that health professionals, such as nurses, do not routinely receive health literacy education as a part of their professionals preparation [18].

Recent studies focus on training and evaluation of health literacy knowledge and communication skills among health workers $[17,19,20]$. In Japan, which has the highest aging rate in the world, the scope of research on health literacy among older adults is expanding [21]. However, research regarding knowledge and practice of supporting health literacy among health professionals in the country is limited. To assess knowledge and practice of health literacy skills among health professionals is important issue for delivering good quality health services in Japan. This study aimed to assess the perception of supporting

health literacy for older adults among staffs in community-based integrated support centers, because the centers play a central role in managing integrated care, including healthcare, long-term care, prevention and daily activities aimed at improving health, welfare, and care for older adults [22]. In addition, centers are one of the primary points of contact for older adults and their family, should they need information and advice related to long-term care.

\section{Methods}

\section{Study design and study participants}

A cross-sectional survey was conducted between October and December 2019. Study participants were care providers who worked in community-based integrated support centers in the Hyogo and Osaka prefectures, Japan. Community-based integrated support centers are established in nationwide in Japan with covering approximately 20,000 inhabitants by each center. In centers, it must be placed three types of professions such as care managers, nurses, and social workers. Questionnaires were posted to all 571 support centers in these prefectures; care managers, nurses, and social workers were requested to participate. Thus, 1731 questionnaires were posted. The study conducted is in accordance with declaration of Helsinki.

\section{Data collection}


The questionnaire comprised knowledge of health literacy, perception of their role in improving health literacy of clients, and practice of communication. Participants were asked about whether they know the term and definition of health literacy, and the degree to which they perceived that improving health literacy of clients was important ("very important," "important," "not important," or "not important at all").

In the Health Literacy Questionnaire (HLQ), participants were asked to rate the following: "To what degree can you do the following statements when you consult with clients?" The questionnaires were developed based on five items of communicative and critical health literacy [23], and the following two items were added: 1) you can assess whether clients understand information adequately, and 2) you can tell clients' self-care goals. Respondents selected from the following options: "strongly disagree," "disagree," "neither disagree nor agree," "agree," or "strongly agree." These were scored from 1 to 5 , respectively. The Cronbach's alpha for the HLQ was 0.87 .

The practice of the communication questionnaire consisted of eight items that asked whether respondents generally do certain activities when they communicate with clients and their families. Specifically, the following activities were considered: 1) speak slowly; 2) avoid terminology and use simple words; 3 ) use illustrations, pictures, and/or videos; 4) limit the amount of information in one time and repeat important points; 5 ) use teach-back methods (ask clients to explain what you have just explained about in their own words); 6) read aloud when clients cannot read; 7) ask whether clients have questions; and 8) confirm whether clients understand what is explained to them. The answers were selected from the following: "not at all," "almost not," "sometimes," or "always." Participants' years of working experience and education level were also asked.

\section{Data analysis}

Descriptive statistics, Chi-square test or Fisher's exact test for categorical data, and the Kruskal-Wallis test for numerical data were used to analyze the demographic characteristics, knowledge and perception of supporting health literacy, and practice of communication based on professional qualifications. The mean and standard deviation of each item and total scores of HLQ were calculated, and the KruskalWallis test was used to analyze the difference in health literacy scores by professional characteristics. Finally, a logistic regression model was used to identify the factors associated with total HLQ scores among the respondents, as the HLQ scores were not normally distributed; the median was set as the cutoff point, i.e., $<26$ and $\geq 26$. All the statistical analyses were conducted using STATA ver16. (StataCorp., TX, USA), and the statistical significance level was set at $<0.05$.

\section{Results}

\section{Participants' demographic and health literacy}

In total, 453 workers (response rate $=26 \%$ ), including 155 care managers $(34 \%), 138$ nurses $(31 \%)$, and 160 social workers (35\%) responded. Educational level and years of working differed significantly, based 
on types of professions. Only 39 (8.8\%) participants knew the term and definition of health literacy. More nurses knew the term and definition of health

literacy and perceived their role in improving health literacy of clients as important, compared to care managers and social workers. Table 1 shows demographic characteristics and health literacy based on professional characteristics.

Table 1

Participants' demographics and health literacy by types of professions

\begin{tabular}{|c|c|c|c|c|}
\hline Variables & $\begin{array}{l}\text { Care } \\
\text { managers } \\
\mathrm{N}=155\end{array}$ & $\begin{array}{l}\text { Nurses } \\
N=138\end{array}$ & $\begin{array}{l}\begin{array}{l}\text { Social } \\
\text { workers }\end{array} \\
N=160\end{array}$ & $\begin{array}{l}\text { p- } \\
\text { value }\end{array}$ \\
\hline Highest level of education & $56(36 \%)$ & $74(54 \%)$ & $22(14 \%)$ & \multirow{3}{*}{$\begin{array}{l}<.001 \\
0.001\end{array}$} \\
\hline Vocational school & $77(49 \%)$ & $62(44 \%)$ & $134(84 \%)$ & \\
\hline \multicolumn{4}{|l|}{ University/ postgraduate } & \\
\hline $\begin{array}{l}\text { Average (standard deviation) working period } \\
\text { (year) }\end{array}$ & $6.5(4.9)$ & $\begin{array}{l}14.8 \\
(11.2)\end{array}$ & $5.8(4.4)$ & 0.001 \\
\hline Knowledge of health literacy & $3(2 \%)$ & $23(17 \%)$ & $13(8 \%)$ & \multirow{4}{*}{$\begin{array}{l}<.001 \\
0.001\end{array}$} \\
\hline Know the term and definition & $46(30 \%)$ & $47(34 \%)$ & $45(28 \%)$ & \\
\hline Know only the term, but not definition & $105(68 \%)$ & $67(49 \%)$ & $101(63 \%)$ & \\
\hline \multicolumn{4}{|l|}{ Do not know neither the term nor definition } & \\
\hline \multirow{2}{*}{$\begin{array}{l}\text { Perception of role in improving health literacy } \\
\text { of clients }\end{array}$} & $37(24 \%)$ & $53(38 \%)$ & $26(16 \%)$ & \multirow{5}{*}{$\begin{array}{l}< \\
0.001\end{array}$} \\
\hline & $110(71 \%)$ & $78(57 \%)$ & $113(71 \%)$ & \\
\hline & $8(5 \%)$ & $2(1 \%)$ & $20(13 \%)$ & \\
\hline Important & & & & \\
\hline Not important/not important at all & & & & \\
\hline
\end{tabular}

Table 2 lists mean and standard deviation of each item and total scores of health literacy questions. Each sub-score and the total scores of health literacy significantly differed by professional qualifications. Further, univariable test shows that the highest scores were among nurses, whereas the lowest scores were among social workers. 
Table 2

Health literacy scores of respondents based on types of professional qualifications

\begin{tabular}{|c|c|c|c|c|}
\hline Items & $\begin{array}{l}\text { Care } \\
\text { managers } \\
\text { Mean } \\
\text { (SD) }\end{array}$ & $\begin{array}{l}\text { Nurses } \\
\text { Mean } \\
\text { (SD) }\end{array}$ & $\begin{array}{l}\text { Social } \\
\text { workers } \\
\text { Mean } \\
\text { (SD) }\end{array}$ & $\begin{array}{l}\text { p- } \\
\text { value }\end{array}$ \\
\hline $\begin{array}{l}\text { 1. You can collect health related information from various } \\
\text { sources such newspaper, books, TV, and/or Internet }\end{array}$ & $3.8(0.68)$ & $\begin{array}{l}3.9 \\
(0.75)\end{array}$ & $\begin{array}{l}3.7 \\
(0.81)\end{array}$ & 0.003 \\
\hline $\begin{array}{l}\text { 2. You can choose information from lots of sources, } \\
\text { based on what you need }\end{array}$ & $3.7(0.73)$ & $\begin{array}{l}3.9 \\
(0.68)\end{array}$ & $\begin{array}{l}3.6 \\
(0.86)\end{array}$ & 0.03 \\
\hline 3. You can understand information and tell others & $3.7(0.71)$ & $\begin{array}{l}3.8 \\
(0.72)\end{array}$ & $\begin{array}{l}3.6 \\
(0.79)\end{array}$ & 0.009 \\
\hline 4. You can evaluate how information is reliable & $3.5(0.74)$ & $\begin{array}{l}3.5 \\
(0.81)\end{array}$ & $\begin{array}{l}3.3 \\
(0.86)\end{array}$ & 0.01 \\
\hline $\begin{array}{l}\text { 5. You can decide the plan and action for improving } \\
\text { health }\end{array}$ & $3.5(0.85)$ & $\begin{array}{l}3.8 \\
(0.73)\end{array}$ & $\begin{array}{l}3.3 \\
(0.9)\end{array}$ & $<.001$ \\
\hline $\begin{array}{l}\text { 6. You can assess whether clients/family members } \\
\text { understood information adequately }\end{array}$ & $3.6(0.8)$ & $\begin{array}{l}3.7 \\
(0.72)\end{array}$ & $\begin{array}{l}3.5 \\
(0.82)\end{array}$ & 0.003 \\
\hline 7. You can communicate the goals of self-care to clients & $3.8(0.73)$ & $\begin{array}{l}3.7 \\
(0.78)\end{array}$ & $\begin{array}{l}3.4 \\
(0.91)\end{array}$ & $\stackrel{<}{0.001}$ \\
\hline Total scores of 7 items & $25.8(3.9)$ & $\begin{array}{l}26.3 \\
(4.1)\end{array}$ & $\begin{array}{l}24.3 \\
(4.3)\end{array}$ & $\dot{0.001}$ \\
\hline
\end{tabular}

The results of univariate and multivariate logistic regression are displayed in Table 3. After controlling for relevant variables, respondents who had longer work experience period and knew the term/definition of health literacy were associated with higher HLQ scores than those who had shorter working period and did not know health literacy. 
Table 3

Results of univariate and multivariate logistic regression models for factors associated with adequate health literacy skills

\begin{tabular}{|c|c|c|}
\hline \multirow[t]{2}{*}{ Variables } & \multicolumn{2}{|c|}{ Odds ratio $(95 \% \mathrm{Cl})$} \\
\hline & Univariable & Multivariable \\
\hline Professional characteristics & Ref. & Ref. \\
\hline Nurse & $0.67(0.41-1.11)$ & $1.04(0.58-1.86)$ \\
\hline Care manager & $0.34(0.21-0.55)$ & $0.60(0.34-1.06)$ \\
\hline \multicolumn{3}{|l|}{ Social worker } \\
\hline Educational level & Ref. & Ref. \\
\hline Vocational school & $0.50(0.32-0.76)$ & $0.75(0.46-1.21)$ \\
\hline \multicolumn{3}{|l|}{ University/post-graduate school } \\
\hline Working experience (year) & $1.06(1.03-1.09)$ & $1.05(1.02-1.09)$ \\
\hline Knowledge of health literacy & Ref. & Ref. \\
\hline Do not know & $1.88(1.26-2.79)$ & $1.86(1.21-2.87)$ \\
\hline Know the term and/or definition & & \\
\hline
\end{tabular}

\section{Practice of communication}

Table 4 lists respondents' practice of communication by types of professions. Over $80 \%$ of the respondents always avoid terminology and use easy words, whereas less than $10 \%$ of the respondents always use illustration/picture/video materials and teach-back methods. Less social workers limit information in one time and repeat important points when they communicate with clients, compared to other professionals. 
Table 4

Participants' practice of communication by types of professional qualifications

\begin{tabular}{|c|c|c|c|c|}
\hline Variables & $\begin{array}{l}\text { Care } \\
\text { managers } \\
\mathrm{N}=155\end{array}$ & $\begin{array}{l}\text { Nurses } \\
N=138\end{array}$ & $\begin{array}{l}\text { Social } \\
\text { workers } \\
N=160\end{array}$ & $\begin{array}{l}\text { p- } \\
\text { value }\end{array}$ \\
\hline $\begin{array}{l}\text { Q1. Speak slowly } \\
\text { Always } \\
\text { Sometimes } \\
\text { Do not do/ rarely }\end{array}$ & $\begin{array}{l}103(66 \%) \\
51(33 \%) \\
1(1 \%)\end{array}$ & $\begin{array}{l}96 \\
(70 \%) \\
40 \\
(29 \%) \\
0\end{array}$ & $\begin{array}{l}108(68 \%) \\
52(33 \%) \\
0\end{array}$ & 0.7 \\
\hline $\begin{array}{l}\text { Q2. Avoid terminology and use easy words } \\
\text { Always } \\
\text { Sometimes } \\
\text { Do not do/ rarely }\end{array}$ & $\begin{array}{l}135(87 \%) \\
18(12 \%) \\
2(1 \%)\end{array}$ & $\begin{array}{l}111 \\
(80 \%) \\
25 \\
(18 \%) \\
2(1 \%)\end{array}$ & $\begin{array}{l}130(81 \%) \\
26(16 \%) \\
1(1 \%)\end{array}$ & 0.5 \\
\hline $\begin{array}{l}\text { Q3. Use illustrations, pictures, and/or videos } \\
\text { Always } \\
\text { Sometimes } \\
\text { Do not do/ rarely }\end{array}$ & $\begin{array}{l}16(10 \%) \\
84(54 \%) \\
55(35 \%)\end{array}$ & $\begin{array}{l}10(7 \%) \\
79 \\
(57 \%) \\
49 \\
(36 \%)\end{array}$ & $\begin{array}{l}16(10 \%) \\
89(56 \%) \\
55(34 \%)\end{array}$ & 0.9 \\
\hline $\begin{array}{l}\text { Q4. Limit information in one time and repeat } \\
\text { important points } \\
\text { Always } \\
\text { Sometimes } \\
\text { Do not do/ rarely }\end{array}$ & $\begin{array}{l}59(38 \%) \\
88(57 \%) \\
6(4 \%)\end{array}$ & $\begin{array}{l}43 \\
(31 \%) \\
84 \\
(61 \%) \\
10(7 \%)\end{array}$ & $\begin{array}{l}33(21 \%) \\
112(70 \%) \\
15(9 \%)\end{array}$ & 0.007 \\
\hline $\begin{array}{l}\text { Q5. Use teach-back methods } \\
\text { Always } \\
\text { Sometimes } \\
\text { Do not do/ rarely }\end{array}$ & $\begin{array}{l}8(5 \%) \\
61(39 \%) \\
86(55 \%)\end{array}$ & $\begin{array}{l}4(3 \%) \\
54 \\
(39 \%) \\
80 \\
(58 \%)\end{array}$ & $\begin{array}{l}5(3 \%) \\
57(36 \%) \\
98(61 \%)\end{array}$ & 0.7 \\
\hline $\begin{array}{l}\text { Q6. Read aloud when clients cannot read } \\
\text { Always } \\
\text { Sometimes }\end{array}$ & $\begin{array}{l}94(61 \%) \\
56(36 \%)\end{array}$ & $\begin{array}{l}93 \\
(67 \%) \\
40 \\
(29 \%)\end{array}$ & $\begin{array}{l}82(51 \%) \\
71(44 \%) \\
7(4 \%)\end{array}$ & 0.07 \\
\hline Do not do/ rarely & & $5(4 \%)$ & & \\
\hline
\end{tabular}




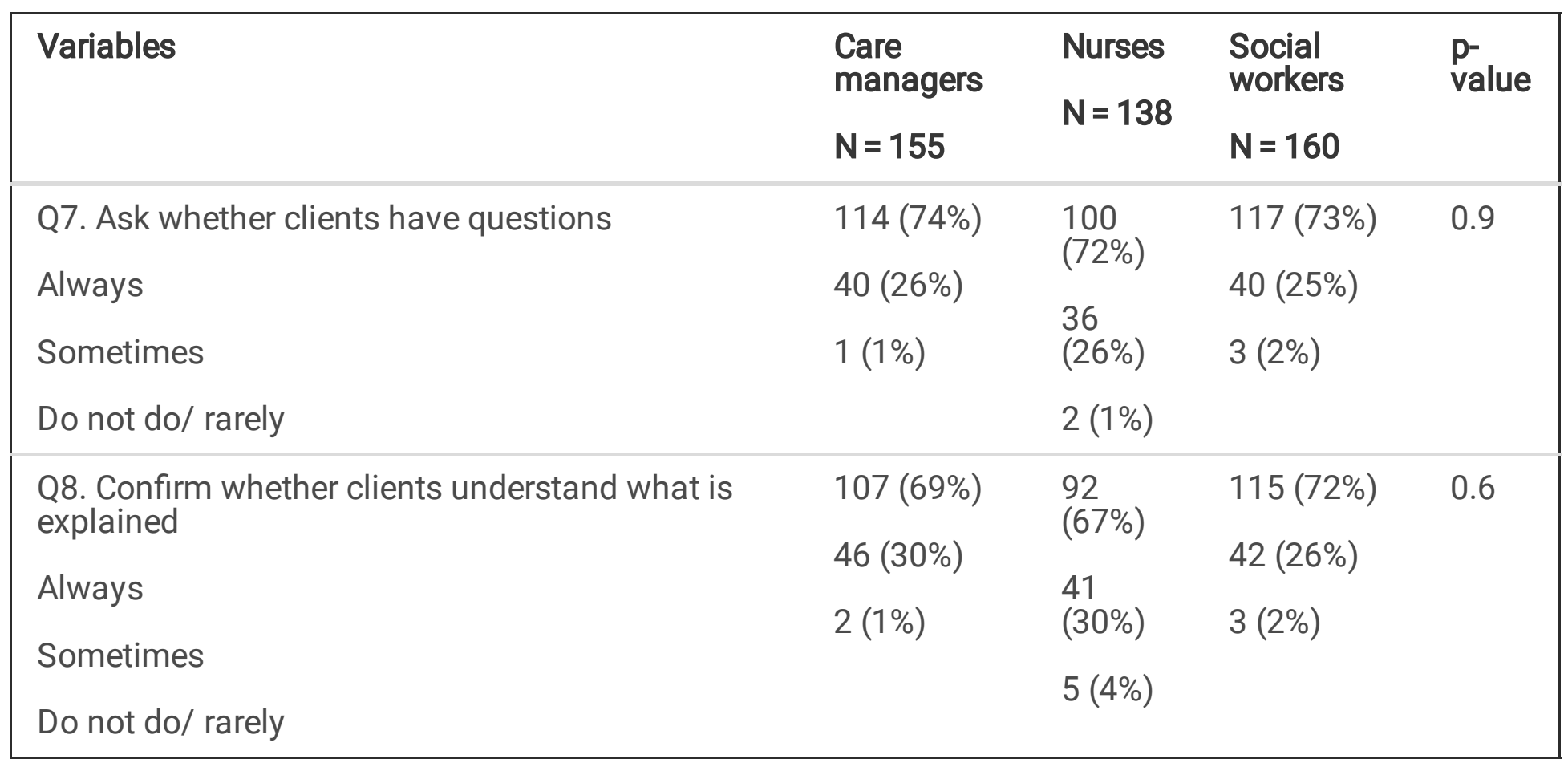

\section{Discussion}

This study aimed to assess knowledge and practice of supporting health literacy for older adults among community care workers, and it shows that a limited number of staff members of community-based integrated support centers know the term and definition of health literacy. Although a vast number of Japanese studies recently reported health literacy, and the Ministry of Health, Labor and Welfare also advocate health literacy and health communication on the website [24], more than $60 \%$ of respondents did not know the term of health literacy. Several studies in other countries also reported that majority of health professionals were unfamiliar with the term health literacy $[16,17]$. Nurses may have had more opportunities to learn about health literacy-related topics, such as health communication and health education, in their graduate institutions; however, nearly $50 \%$ of them answered that they heard about health literacy for the first time, and this number is lower than previous study [17]. Moreover, more than half of the respondents and approximately $40 \%$ of respondents did not use teach-back methods or visual materials in their health literacy work, respectively. Improving basic knowledge of health literacy, including its definition and relationship with health outcomes, is important, because this study revealed that knowledge of health literacy is positively associated with the practice of health literacy among the respondents. In addition, a lower percentage of respondents know that health literacy may be associated with a limited number of respondents using appropriate communication techniques for individuals with lower health literacy levels $[25,26]$. Limited knowledge of health literacy among care workers may be a barrier to support clients' health literacy. Previous research has suggested that poor communication skills of health professionals undermine the opportunity for participants to make use of their health literacy skills in consultations and created a barrier to exchanging information [1]. Due to declining hearing and vision loss may contribute to a decreased ability process health information among older adults [27]. Moreover, older adults with limited health literacy consequence experience more difficulties in 
participating in care consultation [28]. Therefore, improving care workers' communication skills such as using visual materials and teach-back methods is needed to empower older adults in their primary care.

The study found that the perception and practice of health literacy and communication differed by professional qualifications, and was significantly lower among social workers than among nurses. The reasons for this result may be related to the beliefs of social workers that their responsibility is more in terms of welfare than health, and they may relegate supporting clients with low health literacy to nurses. Teaching about health literacy, including the definition of health literacy and discussing techniques for clear communication, are recommended to a broader range of healthcare workers. This is because health communication and information were usually provided by various health staff, including administrators [29]. Moreover, community-based integrated support centers play a central role in providing comprehensive care, including health, long-term care, and social welfare; health literacy skills are required not only for nurses, but also care managers and social workers. The staff of centers need to put in efforts to improve their communication skills, because all of them have equal opportunities to consult and provide reliable information for older adults. Moreover, people with limited health literacy may have limited knowledge and understanding of health that reduces their quality of life [30] and their autonomy in self-care and decision making [31]. The goal of a community-based integrated care system is that older adults live in familiar places with having their dignity, even if they need long-term care. Social workers also require empowering older adults to become more self-assured as they act on their health information, advocate for greater clarity of health information, and learn to navigate the healthcare system more effectively [32].

We also found that the work experience of the respondents was also associated with health literacy scores. Training should also be targeted towards freshers. Several recent studies have evaluated health literacy training for care providers [33,34]. According to these findings, further study is required to develop and evaluate health literacy training for the staffs of community-based integrated support centers.

This study, to the best of our knowledge, is the first survey to assess the health literacy of the staff of community-based integrated care centers. However, due to the low respondence rate and targeting support centers in two prefectures, the results of the study may not be generalized to all community care workers in Japan.

\section{Conclusions}

This study found that the knowledge of health literacy was limited and the perception and practice of health literacy differed by qualifications of the community care workers. To improve the autonomy of care and quality of life of older adults, each staff member of community-based support centers should play a key role in supporting the health literacy of older adults. Comprehensive health literacy and communication training are needed.

\section{Declarations}




\section{Availability of data and materials}

The datasets generated and/or analysed during the current study are not publicly available because consent was not obtained for this use but are available from the corresponding author on reasonable request.

\section{Acknowledgements}

We would like to thank all research participants.

\section{Authors' contributions}

YA and II participated in the design of the study, YA conducted data analyses and drafted manuscript, and II helped to draft the manuscript. All the authors read and approved the final manuscript.

\section{Funding}

This work was supported by Japan Society for the Promotion of Science (JSPS) KAKENHI Grant Number JP18K-10513.

\section{Ethics approval and consent to participate}

All participants and chief managers of the centers received written informed consent, and the questionnaire was anonymous. The study protocol was approved by the Ethical Committee of the Kobe Gakuin University (approval number: Sorin 19-01, Approval date: April 18, 2019).

\section{Consent for publication}

Not applicable.

\section{Competing interests}

There are no financial or non-financial competing interests.

\section{References}

1. Edwards M, Wood F, Davies M, Edwards A: The development of health literacy in patients with a longterm health condition: the health literacy pathway model. BMC Public Health 2012. 12: 130. 
2. Berkman ND, Sheridan SL, Donahue KE, Halpern DJ, Crotty K: Low health literacy and health outcomes: an updated systematic review. Ann Intern Med 2011. 155(2): 97-107.

3. MacLeod S, Musich S, Gulyas S, Cheng Y, Tkatch R, Cempellin D, Bhattarai GR, Hawkins K, Yeh CS: The impact of inadequate health literacy on patient satisfaction, healthcare utilization, and expenditures among older adults. Geriatr Nurs 2017. 38(4): 334-341.

4. Shirooka H, Nishiguchi S, Fukutani N, Adachi D, Tashiro Y, Hotta T, Morino S, Nozaki Y, Hirata H, Yamaguchi M, Aoyama T: Association between comprehensive health literacy and frailty level in community-dwelling older adults: A cross-sectional study in Japan. Geriatr Gerontol Int 2017. 17(5): 804-809.

5. James BD, Boyle PA, Bennett JS, Bennett DA: The impact of health and financial literacy on decision making in community-based older adults. Gerontology 2012. 58(6): 531-539.

6. Naik AD, Street Jr RL, Castillo D, Abraham NS: Health literacy and decision making styles for complex antithrombotic therapy among older multimorbid adults. Patient Educ Couns 2011. 85(3): 499-504.

7. Bunn F, Goodman C, Russell B, Wilson P, Manthorpe J, Rait G, Hodkinson I, Durand MA: Supporting shared decision making for older people with multiple health and social care needs: a realist synthesis. BMC Geriatr 2018. 18(1): 165.

8. Geboers B, de Winter AF, Spoorenberg SLW, Wynia K, Reijneveld SA: The association between health literacy and self-management abilities in adults aged 75 and older, and its moderators. Qual Life Res 2016. 25(11): 2869-2877.

9. Kobayashi LC, Wardle J, Wolf MS, von Wagner C: Aging and Functional Health Literacy: A Systematic Review and Meta-Analysis. J Gerontol B Psychol Sci Soc Sci 2016. 71(3): 445-457.

10. Paasche-Orlow MK, Wolf MS: The causal pathways linking health literacy to health outcomes. Am J Health Behav 2007. 31 Suppl 1: S19-26.

11. Sørensen K, Van den Broucke S, Fullam J, Doyle G, Pelikan J, Slonska Z, Brand H, Consortium Health Literacy Project Europeanet: Health literacy and public health: a systematic review and integration of definitions and models. BMC Public Health 2012. 12:80.

12. World Health Organization: Health literacy toolkit for low-and middle-income countries: A series of information sheets to empower communities and strengthen health systems. WHO Regional Office for South-East Asia: 2015.

13. Greenhalgh T: Health literacy: towards system level solutions. BMJ 2015. 350: h1026.

14. Altin SV, Stock S: The impact of health literacy, patient-centered communication and shared decisionmaking on patients' satisfaction with care received in German primary care practices. BMC Health Serv Res 2016. 16: 450.

15. Guner MD, Ekmekci PE: A Survey Study Evaluating and Comparing the Health Literacy Knowledge and Communication Skills Used by Nurses and Physicians. Inquiry 2019. 56: 46958019865831.

16. Lambert M, Luke J, Downey B, Crengle S, Kelaher M, Reid S, Smylieet J: Health literacy: health professionals' understandings and their perceptions of barriers that Indigenous patients encounter. BMC Health Serv Res 2014. 14: 614. 
17. Macabasco-O'Connell A, Fry-Bowers EK: Knowledge and perceptions of health literacy among nursing professionals. J Health Commun 2011. 16 Suppl 3:295-307.

18. Dickens C, Lambert BL, Cromwell T, Piano MR: Nurse overestimation of patients' health literacy. $J$ Health Commun 2013. 18 Suppl 1: 62-69.

19. Pagels P, Kindratt T, Arnold D, Brandt J, Woodfin G, Gimpel N: Training Family Medicine Residents in Effective Communication Skills While Utilizing Promotoras as Standardized Patients in OSCEs: A Health Literacy Curriculum. Int J Family Med 2015. 2015:129187.

20. Wittenberg E, Ferrell B, Kanter E, Buller H: Health Literacy: Exploring Nursing Challenges to Providing Support and Understanding. Clin J Oncol Nurs 2018. 22(1): 53-61.

21. Uemura $\mathrm{K}$, Yamada M, Okamoto H: Effects of Active Learning on Health Literacy and Behavior in Older Adults: A Randomized Controlled Trial. J Am Geriatr Soc 2018. 66(9): 1721-1729.

22. Hatano Y, Matsumoto M, Okita M, Inoue K, Takeuchi K, Tsutsui T, Nishimura S, Hayashi T: The vanguard of community-based integrated care in Japan: The effect of a rural town on national policy. Int J Integr Care 2017. 17(2): 2.

23. Ishikawa H, Nomura K, Sato M, Yano E: Developing a measure of communicative and critical health literacy: a pilot study of Japanese office workers. Health Promot Int 2008. 23(3): 269-274.

24. Ministry of Health, Labour, and Welfare: Evidence-based Japanese integrated medicine 2015; Available from: https://www.ejim.ncgg.go.jp/pro/ communication/index.html. (Access date: December 23, 2020).

25. Negarandeh R, Mahmoodi H, Noktehdan $H$, Heshmat R, Shakibazadehet E: Teach back and pictorial image educational strategies on knowledge about diabetes and medication/dietary adherence among low health literate patients with type 2 diabetes. Prim Care Diabetes 2013. 7(2):111-118.

26. Yen PH, Leasure AR: Use and Effectiveness of the Teach-Back Method in Patient Education and Health Outcomes. Fed Pract 2019. 36(6): 284-289.

27. Speros Cl: More than words: promoting health literacy in older adults. OJIN2009. 14(3): 5.

28. McCaffery KJ, Smith SK, Wolf M: The challenge of shared decision making among patients with lower literacy: a framework for research and development. Med Decis Making 2010. 30(1): 35-44.

29. Parker RM, Ratzan SC, Lurie N: Health literacy: a policy challenge for advancing high-quality health care. Health Aff (Millwood) 2003. 22(4):147-153.

30. Panagioti M, Skevington SM, Hann M, Howells K, Blakemore A, Reeves D, Bower P: Effect of health literacy on the quality of life of older patients with long-term conditions: a large cohort study in UK general practice. Qual Life Res 2018. 27(5): 1257-1268.

31. Erlen JA: Functional health illiteracy. Ethical concerns. Orthop Nurs 2004. 23(2): 150-153.

32. Findley A: Low health literacy and older adults: meanings, problems, and recommendations for social work. Soc Work Health Care 2015. 54(1): 65-81.

33. Goto A, Lai AY, Rudd RE: Health Literacy Training for Public Health Nurses in Fukushima: A Multi-site Program Evaluation. Japan Med Assoc J 2015. 58(3): 69-77. 
34. Mackert M, Ball J, Lopez N: Health literacy awareness training for healthcare workers: improving knowledge and intentions to use clear communication techniques. Patient Educ Couns 2011. 85(3): e225-228. 